13. Сидякина Л.В. Некоторые почвенные характеристики основных фитоценозов горы Могутова // Экологический сборник 5: Труды молодых ученых Поволжья: междунар. науч. конф. / под ред. канд. биол. наук С.А. Сенатора, О.В. Мухортовой и проф. С.В. Саксонова. Тольятти: ИЭВБ РАН, «Кассандра», 2015. C. 345-351.

14. Сидякина Л.В. Кислотность, влажность почвенного покрова и фитомасса растительных сообществ горы Могутова (Самарская Лука) в 20132014 гг. // Известия Самарского научного центра Российской академии наук. 2015. Т. 17, № 4-5. С. 892-896.

15. Сидякина Л.В. Охраняемые растения в травяных сообществах горы Могутова (НП «Самарская Лука») // Природное наследие России: сборник научных статей междунар. науч. конф., посв. 100-летию национального заповедного дела и Году экологии в России / под ред. Л.А. Новиковой. Пенза: ПГУ, 2017. С. 323-326.

16. Сидякина Л.В., Васюков В.М. Фитоценотическая характеристика основных лесных сообществ горы Могутова (национальный парк «Самарская Лу- ка», Самарская область) // История ботаники в России. К 100-летнему юбилею РБО. Сборник статей междунар. науч. конф. Т. 3. Современное развитие ботаники в России (штрихи). Тольятти: Кассандра, 2015. C. $157-167$.

17. Ипатов В.С. Методы описания фитоценоза. СПб., 2000. 56 с.

18. Ипатов В.С., Мирин Д.М. Описание фитоценоза: методические рекомендации. СПб., 2008. 71 с.

19. International Plant Names Index [El. resource] // http://ipni.org.

20. Спрыгин И.И. Выход пород Татарского яруса Пермской системы в Заволжье, как один из центров видообразования, в группе калькофильных растений // Советская ботаника. 1934. № 4. С. 61-74.

21. Конева Н.В., Сидякина Л.В. Экологические и ботанико-географические закономерности сложения флоры Самарской Луки // Экология и география растений и растительных сообществ: материалы IV междунар. науч. конф. (Екатеринбург, 16-19 апреля 2018 г.). Екатеринбург: Изд-во Урал. ун-та; Гуманитарный ун-т, 2018. С. 441-443.

\title{
ZHIGULI HILLS ENDEMIC SPECIES IN THE MOGUTOVA MOUNTAIN FLORA
}

(C) 2018

\author{
Sidyakina Larisa Valerievna, engineer-researcher of Phytodiversity Problems Laboratory \\ Vasjukov Vladimir Mikhailovich, candidate of biological sciences, \\ researcher of Phytodiversity Problems Laboratory \\ Saksonov Sergey Vladimirovich, doctor of biological sciences, professor, \\ acting director, head of Phytodiversity Problems Laboratory \\ Institute of Ecology of the Volga River Basin of Russian Academy of Sciences \\ (Togliatti, Samara Region, Russian Federation)
}

\begin{abstract}
Mogutova mountain flora (Zhiguli hill, Samara Region) has about 700 species of vascular plants, 14 species are included in the Red Book of the Russian Federation (2008), 50 species are included in the Red Book of the Samara Region (2017), 7 species are the endemics of the Zhiguli hills. On the Mogutova mountain 48 plant associations were described: 36 associations are represented by forest vegetation, 1 Association is represented by shrubs, 11 associations are represented by herbaceous vegetation. In eight described associations there are 6 endemic species of the Zhiguli hills: in Cerasus fruticosa + Caragana frutex association one endemic species is found - Euphorbia zhiguliensis; in Stipa pennata - Caragana frutex association there are 3 endemics - Cerastium zhigulense, Gypsophila juzepczukii and Thymus zheguliensis; in Stipa capillata + Herbae stepposae and Stipa capillata + Echinops ruthenicus associations there is only Thymus zheguliensis; in Herbae stepposae + Stipa pulcherrima and Stipa pennata + Helianthemum nummularium associations there are 2 endemic species - Gypsophila juzepczukii and Thymus zheguliensis; in Thymus zheguliensis association there are 4 endemics - Cerastium zhigulense, Gypsophila juzepczukii, Sisymbrium pinnatisectum, Thymus zheguliensis; in Schevereckia hyperborea association Poa saksonovii is revealed. The endemics of the Zhiguli hills: Euphorbia zhiguliensis and Thymus zheguliensis are protected at the Federal level, and Cerastium zhigulense, Gypsophila juzepczukii and Poa saksonovii are protected at the regional level.

Keywords: endemic; flora; vascular plants; Cerastium zhigulense; Euphorbia zhiguliensis; Gypsophila juzepczukii; Poa saksonovii; Sisymbrium pinnatisectum; Thymus zheguliensis; plant associations; Red book of Russian Federation; Red book of Samara Region; Zhiguli hill; Mogutova mountain.
\end{abstract}

УДК 574.632

Статья поступила в редакцию 25.06.2018

\section{ВЛИЯНИЕ ХОЗЯЙСТВЕННОЙ ДЕЯТЕЛЬНОСТИ НА ЭКОЛОГИЧЕСКОЕ СОСТОЯНИЕ ВОДОЕМОВ ГОРОДА ИШИМА}

(C) 2018

Суппес Наталья Евгеньевна, кандидат биологических наук, доцент кафедры биологии, географии и методики их преподавания Ииимский педагогический институт имени П.П. Ершова (филиал)

Тюменского государственного университета (2. Ииим, Тюменская область, Российская Федераиия)

Аннотация. В данной статье рассматривается проблема состояния водоемов города Ишима в градиенте антропогенной нагрузки. В ходе исследования было выявлено, что водные объекты испытывают некоторое 
негативное влияние при осуществлении хозяйственной деятельности населением. Определены основные их направления: попадание стоков промышленных предприятий в водоемы города, строительство и эксплуатация инженерных сооружений, деятельность частного жилого сектора. Для оценки состояния водоемов были использованы результаты визуальной оценки состояния русел рек и прибрежной зоны водоемов, органолептические показатели воды (мутность, цвет и запах), анализ гидробиологических исследований (определение степени сапробности водоемов, с использованием в качестве индикаторов ресничных инфузорий). Исследование показало, что состояние всех водоемов удовлетворительное, а влияние не является критичным, так как предприятия легкой и пищевой промышленности города не являются источниками мощного химического, органического и другого загрязнения; визуальная оценка не выявила значительной деформации русла и изменений в прибрежной зоне; воздействия частного сектора носят локальный характер и не вызывают значительного органического загрязнения.

Ключевые слова: хозяйственная деятельность; антропогенное влияние; экологическое состояние; экологическая оценка состояния водных объектов; эвтрофикация водоемов; город Ишим; органическое загрязнение; деформация русла; производственные сточные воды; визуальная оценка состояния; органолептические показатели; сапробность; ресничные инфузории; метод Пантле и Бука; фаунистический список.

\section{Введение}

В настоящее время важной является проблема взаимодействия природы и общества. В связи с развитием индустриального общества хозяйственная деятельность человека приводит к значительным изменениям водных экосистем, которые на данный момент достигли большого масштабного роста [1]. В результате антропогенного влияния происходят важные изменения морфометрических, гидрологических, химических и других характеристик водоемов. Часто это находит отражение в изменении структуры, продуктивности и состояния водных экосистем, может приводить к прогрессированию процессов эвтрофикации антропогенного характера [2, с. 70].

Для того чтобы оценить весь спектр изменений, необходимо своевременно и систематически проводить экологическую оценку состояния водных объектов. Оценивая экологическое состояние водных объектов, необходимо учитывать наличие количества жителей населенных пунктов, сферу деятельности предприятий, места свалок, дамбовых сооружений, а также количество жилищно-коммунальных отходов [3, с. 163-171; 4, с. 723-731].

И.С. Большинская [5] утверждает, что в малых и средних городах экологическое состояние водных экосистем может достигать критической отметки. Прежде всего, это связано с развитием промышленности, загрязнением водоемов, бурным ростом численности населения и усилением хозяйственной деятельности.

В настоящее время в научной литературе обзорно и фрагментарно освещены исследования влияния хозяйственной деятельности на водные объекты территорий, сопредельных с территорией Западной Сибири [6-13]. Однако для получения полного представления о влиянии хозяйственной деятельности на водоемы города Ишима необходимы дополнительные и систематические исследования. Это обосновывает актуальность исследования и определяет её цель изучение влияния хозяйственной деятельности на состояние водоемов города Ишима.

\section{Объекты исследования}

Объектом исследования послужили шесть водоемов, находящихся в пределах черты города Ишима, а именно р. Ишим, р. Карасуль, р. Мергень, оз. Чертово, оз. Аникино и старица Ишимчик.

\section{Материал и методика исследования}

Исследования проводились на территории города Ишима, который расположен в южной части Тюменской области. Он находится на территории Уральского федерального округа Российской Федерации на Западно-Сибирской равнине, на террасах и пойме p. Ишим в лесостепной зоне. Общая площадь города Ишима составляет 4610 га, численность жителей не превышает 66 тыс. человек. Территория г. Ишима со всех сторон окружена водными объектами: левобережная сторона расположена на р. Ишим, северная и восточная стороны ограничены р. Карасуль, а с запада находится р. Мергень. Кроме этого, с запада к городу примыкают крупные озера - оз. Аникино и оз. Мергень [14; 15].

Исследование влияния хозяйственной деятельности проводилось в 2016 году и в 2017 году в весенний периоды с использованием таких методов, как: метод визуальной оценки состояния водоемов и их прибрежных зон [16; 17, с. 17-25], гидробиологического (метод Пантле и Бука - определение степени сапробности воды и метод Головина - графический способ распределения видов по индикаторной значимости) $[18$, с. $337-342 ; 19$, с. $27-65 ; 20]$ и гидрологического (определение органолептических показателей: цветность, мутность, запах) методов.

\section{Результаты исследований и их обсуждение}

В ходе исследования, проведенного на территории г. Ишима, были определены основные виды хозяйственной деятельности населения, оказывающие влияние на состояние водоемов города.

Среди них можно выделить три основные группьl.

К первой группе относится строительство $u$ эксплуатация инженерных сооружений, ко второй стоки промышленных предприятий города, к третьей - виды хозяйственной деятельности, осуществляемые населением частного сектора, которое проживает непосредственно вблизи от водоемов.

Проводя визуальную оценку водоемов города, было отмечено присутствие на них инженерных сооружений в виде мостов, дамб, набережной.

На р. Ишим выявлен ряд дамбовых сооружений, расположенных по ул. Курганская, возле Промышленного и Восточного узла, также между железнодорожным мостом и очистными сооружениями организации «Водоканал». 
Суппес Н.Е.

Влияние хозяйственной деятельности на экологическое состояние водоемов..

03.02.00 - общая биология

Дамбы возведены для регулирования тока воды и защиты местного населения от затопления. Однако в результате прорыва дамб в 2016 и 2017 годах в весенний период произошло затопление обширной территории в г. Ишиме и близ расположенных окрестностей, в результате чего были размыты выгребные ямы, туалеты, свалки, огороды усадебной жилой застройки, сельскохозяйственные угодья. Повсюду были разбросаны доски, палки, строительный материл, макулатура, пластмассовые бутылки, полиэтиленовые пакеты. В это время участились случаи миграции грызунов, которые обнаруживались в затопленных частных жилых и хозяйственных постройках. Все это привело к обострению ситуации с увеличением риска заражения животных и людей различными острыми кишечными и природно-очаговыми инфекциями (геморрагической лихорадкой с почечным синдромом, туляремией, лептоспирозом).

Помимо дамбовых сооружении, оказывающих влияние на состояние русла реки Ишим, в 2013 г. была построена пешеходная набережная по ул. Береговой в районе городского парка.

При постройке набережной был проведен целый комплекс строительных работ: уборка намытых островов в русле реки Ишим, берегоукрепление с помощью шпунтов, выполнена отсыпка ломаными камнями скальной породы, обустроена прогулочная зона с пешеходными дорожками и причалом. Общая протяженность набережной составила 520 м, площадь 8 км², включая территорию городского пляжа, которая является составной частью рекреационной зоны г. Ишима. В ходе строительных работ по возведению набережной было оказано воздействие на р. Ишим в виде попадания строительного мусора, осыпания берегового грунта, который перемешивался с водой и приводил к увеличению мутности воды в реке. В настоящее время сильного влияния набережной отметить нельзя, тем не менее она является локальным местом загрязнения, прежде всего оно выражается в загрязнении упаковочным материалом, пластиковыми, стеклянными и жестяными банками, бытовым мусором, а также горюче-смазочным материалом от рядом находящейся лодочной станции.

Автомобильные мосты с потоком легковых и грузовых машин оказывают определенное влияние из-за выбросов выхлопных газов, которые являются основной причиной повышения концентрации токсичных веществ и канцерогенов, частицы веществ затем осаждаются на поверхность водоема. Таких мостов на р. Мергень семь, на р. Карасуль четыре, а на р. Ишим два.

Следующим антропогенным фактором, влияющим на состояние водных объектов, являются промышленные предприятия г. Ишима. В зависимости от площади и вида деятельности, их сточные воды загрязняют водоемы различными компонентами. А.Ф. Щеглов [14] в своей монографии выделяет около 13 действующих предприятий на территории города Ишима.

Для г. Ишима характерно присутствие в основном предприятий легкой и пищевой промышленности, которые занимают одно из лидирующих мест по расходу воды и являются источниками загрязнения. Пищевая промышленность представлена мясной и молочной промышленностью.
Производственные сточные воды мясной промышленности (ООО «Ишимский мясокомбинат») по характеру и степени загрязнения могут быть двух видов: сточные воды, которые образуются в зажиренных цехах, где осуществляют разделку мяса и забой скота, и стоки с цехов, где происходит переработка мяса. Другой вид сточных вод образуется в незажиренном цехе, где осуществляется содержание скота, и в инфицированном цехе, который представлен в виде изолятора для животных и нужен для карантина. Для каждой из этих категорий предусматриваются разные сети канализации. В стоках присутствует значительное количество органики в виде остатков мяса, костей после разделки туш, а также навоз и солома из цехов содержания скота и корма. Кроме того, в сточных водах содержатся и минеральные примеси.

Сточные воды предприятий молочной промышленности (филиал АО «Золотые луга» «Молочный комбинат «Ишимский»), также подразделяются на две группы: бытовые, после уборки бытовых и подсобных помещений, и производственные, после промывки готовых молочных изделий и мойки оборудования. Они содержат большое количество примесей органической природы, а также обнаруживается присутствие специальных моющих средств.

Также сточные воды предприятий молочной и мясной промышленности характеризуются высокой бактериальной опасностью, представленной в виде патогенных микроорганизмов, например, яиц глистов и кишечных паразитов.

Производственные сточные воды от предприятий г. Ишима поступают на станцию очистных сооружения «Водоканал» и после этого сбрасываются в p. Ишим. Основную нагрузку от сточных вод предприятий реки и озера испытывают из-за недостаточной эффективности работы очистных сооружений и их перегруженности.

Немаловажное значение для водных объектов г. Ишима имеет влияние хозяйственной деятельности, которое оказывает частный жилой сектор, расположенный по берегам рек и озер.

В ходе исследования р. Ишим было выявлено, что на ее узкой прибрежной полосе с левой стороны располагается частный жилой сектор (район Плодопитомника, Ишимсельмаш-1,2, ТОС Киселевский и Серебрянка), часто вплотную подходящий к кромке воды с надворными туалетами, дачными территориями, огородами, которые оказывают прямое и опосредованное воздействие на водную экосистему. Кроме того, практически все садовые участки находятся на наклонной плоскости, и в весенний период с временными водотоками происходит смыв органических и других веществ в реку.

Река Карасуль является правым притоком р. Ишим, расположена в правой части города. Со всех сторон реку окружает частный жилой сектор, расположенный на территории водоохранных зон, где установлены соответствующие экологические требования для предотвращения загрязнения.

Реку Мергень также практически со всех сторон окружает частный жилой сектор. Несоблюдение норм вблизи и в пределах водоохранных зон наблюдается по ул. Центральная, Магистральная, Приозерная, вблизи нависающего моста по ул. Врачей Кали- 
ниных. Здесь отмечено наличие многочисленных бытовых и строительных отходов в виде пластиковых и пластмассовых бутылок, досок, цемента, бытового мусора, строительного и упаковочного материала.

Вдоль оз. Аникино и оз. Чертово и по их окраинам частный жилой сектор практически отсутствует, за исключением ул. Центральной, где частный сектор подходит вплотную к оз. Аникино. Имеются несанкционированные свалки бытового мусора в пределах водоохраной зоны.

Методом визуальной оценки состояния прибрежной зоны исследуемых водоемов выявлены особенности морфометрических характеристик русел рек и озерных котловин, исследовано общее состояние прибрежной территории, определено наличие источников органического и другого загрязнения, локальные скопление бытовых и хозяйственных отходов, видовой состав водной и прибрежной растительности. Анализируя полученные результаты, можно отметить удовлетворительное состояние береговой зоны водных объектов.

Органолептическая оценка свойства воды в водоемах г. Ишима включала в себя определение таких показателей, как: запах, цветность и мутность воды.

Органолептический показатель мутности - отрицательный для р. Ишим. В старице Ишимчик и оз. Чертово, на р. Карасуль в воде также не было выявлено взвешенных частиц, за исключением проб, которые были отобраны на станциях 2 и 3, расположенных по ул. 2-я Северная и ул. Ленина, там показатель мутности - слабомутный. Аналогичная ситуация по р. Мергень, т.к. практически на всем ее протяжении от ул. Смычка до ул. 6-я Западная мутность воды отсутствует, а лишь на 2 и 4 станциях, расположенных по ул. Челюскинцев и ул. Сурикова, в воде было обнаружено присутствие небольшого количества взвешенных частиц, что определяет воду по шкале как слабо-мутную. В оз. Аникино все отобранные пробы с разных станций свидетельствует о наличии взвешенных частиц - вода слабо-мутная.

По показателю цветности воды выявлено, что в p. Ишим и р. Мергень данный показатель варьируют от светло-желтого до слабо-желтого, а в р. Карасуль и старице Ишимчик цвет воды варьирует от светложелтого до желтого оттенков. Желтый оттенок является следствием присутствия в воде продуктов разложения. На озере Чертово на всех станциях определен показатель воды как слабо-желтая, на озере Аникино цвет воды имеет светло-желтый оттенок.

Согласно анализу показателя запаха воды, все отобранные пробы имеют землянистый запах или его отсутствие, за исключением двух водоемов: р. Карасуль и старицы Ишимчик, у которых был обнаружен гнилостный запах.

Результаты авторского исследования органолептических показателей (цвет, мутность, запах) реки Ишим не противоречат данным «ФГУЗ Центр гигиены и эпидемиологии по Ишимскому, Абатскому, Викуловскому районам» 2015-2017 годы.

В рамках гидробиологических исследований отбор проб производился на пяти станциях каждого из шести водоемов. Всего в отобранных пробах было обнаружено 35 видов инфузории, которые относятся к 9 семействам и 22 родам. В р. Ишим было обнару- жено 16 видов, на р. Карасуль 13 видов, в реке Мергень 10 видов, на старице Ишимчик видовой состав равен 13 видами, на оз. Аникино 12 видов, оз. Чертово 15 видов.

На основе проведенных исследований был составлен фаунистический список инфузории водоемов г. Ишима. Анализ результатов исследования показал, что каждый водоем характеризуется своим видовым разнообразием ресничных инфузорий. Количественное распределение видовых составов оказалось примерно одинаковым в пределах от 10 до 16 видов по каждому водоему.

По количеству видов доминируют такие семейства, как: Frontoniidae, Euplotidae, Halteriidae, Oхуtrichidae, Vorticellidae. Наибольшей численность в изучаемых пробах обладают виды: Colpidium colpoda Stein, 1860; Euplotes patella O.F. Muller, 1786; Oxytricha fallax Stein, 1859. Фоновыми видами оказались: Halteria grandinella O.F. Muller, 1786; Strombidium mirable Penard, 1961; Stilonichia putrina Ehrenberg, 1838; Stilonichia mytilus Ehrenberg, 1838; Vorticella companulla Ehrenberg, 1831; Vorticella picta Ehrenberg, 1831, которые составляют около $47 \%$ от общего количества встреченных ресничных инфузорий. К менее часто встречающимся видам относятся: Carchesium polipinum Linne, 1758; Euplotes charon O.F. Muller, 1786; Paramecium aurelia Ehrenberg, 1838; Paramecium caudatum Ehrenberg, 1838; Prodon teres Ehrenberg, 1838, а к редко встречающимся относятся оставшиеся виды, которые составляют около $25 \%$ от общего количества встреченных инфузорий.

Анализируя видовой состав инфузории по индикаторной значимости, оказалось, что большинство видов относится к альфа-мезосапробной и бетамезосапробной группе. Однако для каждого водоема распределение видов по индикаторной значимости своеобразно.

Для водоемов р. Мергень и старицы Ишимчик распределение оказалось примерно одинаковым, в них обнаружены только альфа и бета-мезосапробные виды, в р. Карасуль помимо альфа- и бета-мезосапробных видов присутствуют олигосапробные виды (Frontonia acuminate Ehrenberg, 1888), а в оз. Аникино, оз. Чертово, наоборот, были обнаружены альфа-бета-мезосапробные и полисапробные виды (Colpidium colpoda Stein, 1860). В пробах р. Ишим обнаружены виды инфузорий всех четырех зон сапробности, но преобладающими являются альфамезосапробные виды инфузорий. Большое количество бета-мезосапробов и альфа-мезосапробов, характерное практически для всех водоемов города (за исключением р. Ишим), может быть следствием прогрессивной естественной эвтрофикации. В результате чего водоемы интенсивно зарастают водной растительностью, на фоне общего снижения уровня воды, при незначительной скорости течения.

Также причиной накопления органического вещества в воде может быть ведение хозяйственной деятельности, в результате чего происходит смыв органики с прибрежной территории, на которой располагается частный сектор и сброс сточных вод промышленных предприятий города.

Используя метод Пантле и Бука, был рассчитан индекс сапробности для каждого из шести водоемов (табл. 1). 
Таблица 1 - Индекс сапробности водоемов г. Ишима (2016-2017 гг.)

\begin{tabular}{|l|c|c|c|c|c|c|}
\hline Станций отбора проб & Р. Ишим & Р. Мергень & Р. Карасуль & $\begin{array}{c}\text { Старица } \\
\text { Ишимчик }\end{array}$ & Оз. Аникино & Оз. Чертовое \\
\hline $\begin{array}{l}\text { Средний показатель } \\
\text { индекса сапробности }\end{array}$ & 2,63 & 2,29 & 2,16 & 2,44 & 2,43 & 2,36 \\
\hline $\begin{array}{l}\text { Зона сапробности во- } \\
\text { доема }\end{array}$ & $\begin{array}{c}\text { альфа-мезо- } \\
\text { сапробная }\end{array}$ & $\begin{array}{c}\text { бета-мезо- } \\
\text { сапробная }\end{array}$ & $\begin{array}{c}\text { бета-мезо- } \\
\text { сапробная }\end{array}$ & $\begin{array}{c}\text { бета-мезо- } \\
\text { сапробная }\end{array}$ & $\begin{array}{c}\text { бета-мезо- } \\
\text { сапробная }\end{array}$ & $\begin{array}{c}\text { бета-мезо- } \\
\text { сапробная }\end{array}$ \\
\hline
\end{tabular}

Воды в р. Ишим (индекс сапробности - 2,63) соответствуют альфа-мезосапробной зоне - зоне умеренного органического загрязнения.

Альфа-мезосапробная зона (зоны умеренного загрязнения) характеризуется следующими условиями среды: полуанаэробные, биохимические процессы восстановительно-окислительные, присутствует сероводород. Количество сапрофитных бактерий в данной зоне определяется десятками и сотнями тысяч в 1 мл. Железо находится в окисной и закисной формах. Ил серого цвета. Содержатся организмы, приспособленные к недостатку кислорода и значительному содержанию углекислоты. Преобладают растительные организмы с гетеротрофным и микотрофным питанием [11].

Все остальные водоемы относятся к бета-мезосапробной зоне - зоне слабого органического загрязнения. Индекс сапробности варьирует от 2,16-2,44.

Бета-мезосапробная зона характеризуется преобладанием продуктов минерализации белков, таких как аммонийные соединения, нитраты и нитриты. В данной зоне кислорода обычно достаточно. Содержание кислорода и углекислоты колеблется в зависимости от времени суток: днем избыток кислорода, дефицит углекислоты; ночью - наоборот. В этих водах представлены разнообразные животные и растительные организмы. Много организмов с автотрофным питанием. Нередко наблюдается цветение воды, так как сильно развит фитопланктон [11].

Несмотря на то что р. Ишим является более крупной рекой по сравнению с р. Мергень и р. Карасуль, а также характеризуется большей скоростью течения и обладает более интенсивными процессами самоочищения, река относится к зоне умеренного загрязнения.

Объяснением этому может служить следующее:

1. В результате весенних половодий 2016-2017 годов с затопленных территорий осуществлялся массовый смыв различных веществ, в том числе и органической природы, в воду реки.

2. Происходит сброс недоочищенных сточных вод с предприятий пищевой промышленности города в главную водную артерию.

3. Попадание органических веществ и бытовых отходов в результате ведения хозяйственной деятельности жителями частного сектора, расположенного в пределах водоохранной зоны р. Ишим.

Слабое органическое загрязнение, характерное для р. Карасуль, р. Мергень, по сравнению с р. Ишим, объясняется тем, что весенние половодья 20162017 годов привели к значительному подъему воды в реках. Также в летний период 2017 году в рамках профилактических противопаводковых мероприятий было значительно расширено русло реки и уничтожена прибрежная растительность, что привело к уве- личению скорости течения воды и замедлению процессов естественной эвтрофикации.

\section{Выводы}

1. Определены основные виды хозяйственной деятельности, влияющие на состояние водоемов в пределах г. Ишима. К ним относятся: стоки промышленных предприятий, строительство и эксплуатация инженерных сооружений, деятельность частного жилого сектора.

2. Метод визуальной оценки состояния водоемов показал, что значительных изменений в морфологии объектов нет. На водных объектах или вблизи них располагаются инженерные сооружения (набережная, мосты, дамбы), в пределах водоохранных зон присутствует частный сектор с надворными постройками, огородами, загонами для скота, выгребными ямами и свалками бытового мусора.

3. В городе Ишиме, часто в непосредственной близости к водным объектам, располагаются предприятия пищевой и легкой промышленности. Негативные последствия их деятельности по отношению к водным экосистемам выражается в виде стока органических и химических веществ при промывке сырья и оборудования (бочек, фляг, цистерн и др.). При строительстве таких инженерных сооружений, как автомобильные мосты, набережная и дамбы, и при последующей их эксплуатации происходит сброс строительного материала, осыпание берегов, некоторые изменения морфологии русла. Частный жилой сектор, располагаясь в пределах водоохранных зон, нарушает предписания, соответствующие деятельности на данной территории: загрязняет воду бытовым мусором, отходами органической природы, нерационально использует воду и не имеет централизованной канализационной системы.

4. По результатам органолептических показателей вода слабо-мутная на р. Карасуль, р. Мергень, о3. Аникино, в остальных исследуемых водоемах вода прозрачная. Цвет воды во всех водоемах варьирует от светло-желтой до желтой, запах землянистый или отсутствует, за исключением р. Карасуль и старицы Ишимчик, где он гнилостный.

5. Гидробиологический анализ показал, что в отобранных пробах было выявлено 35 видов инфузорий, большинство из которых относится к альфамезосапробным видам. Согласно расчетам индекса сапробности, показатели всех водоемов г. Ишима оказались в пределах 2,16-2,63, что соответствует альфа-мезосапробной зоне (р. Ишим) - зоне умеренного загрязнения и бета-мезосапробной зоне (р. Карасуль, р. Мергень, оз. Аникино, оз. Чертово, старица Ишимчик) - зоне, которая характеризуется низкими показателями присутствия органического вещества в воде. 


\section{Список литературы:}

1. Никитин О.В., Латыпова В.3. Экотехнология восстановления водных объектов: конспект лекций [Электронный ресурс] // Электронный архив КПФУ. http://dspace.kpfu.ru/xmlui/bitstream/handle/net/21987/0 2_81_kl-000842.pdf.

2. Выхристюк Л.А., Зинченко Т.Д., Шитиков В.К. Комплексная оценка экологического состояния равнинных рек в условиях антропогенных воздействий // Научные аспекты экологических проблем России. СПб.: Гидрометеоиздат, 2001. С. 70.

3. Шикломанов И.А., Трусилова Т.М., Севидова Л.П. Влияние хозяйственной деятельности на речной сток // Вестник Тюменского университета. Сер. 2 «Естественные науки». 2003. № 2. С. 163-171.

4. Шварцев С.Л. Эколого-геохимическое состояние речных вод Средней Оби // Водные ресурсы. 1996. Т. 23, № 6. С. 723-731.

5. Большинская И.С. О проблемах больших и малых городах // Проблемы экономики. 2012. № 4. C. $68-73$.

6. Кобетаева Н.К., Бадмаева С.Э. Мониторинг экологического состояния поверхностных вод на примере реки Ишим на территории Республики Казахстан // Вестник Краснодарского аграрного университета. Сер. 2 «Экология и природопользование». 2012. № 2. C. 150-154.

7. Левых А.Ю., Пузынин Г.Г., Ермолаева А.В. Мониторинг состояния экосистем на территории города Ишима // Известия Самар. науч. центра Рос. акад. наук. Т. 12 «Мониторинг окружающей среды». 2010. № 1-8. С. 1935-1939.

8. Вешкурцева Т.М. Влияние хозяйственной деятельности на русловые процессы реки Ишим // Вестник Тюмен. ун-та. Сер. 2 «Экология и природопользования». 2013. № 4. С. 143-153.

9. Токарь О.Е. Состояние и проблемы очистки сточных вод г. Ишима (Тюменская область) // Естественные науки: сб. науч. тр. Сургут, 2003. Вып. 12. C. $187-195$.

10. Шилькрот Г.С. Причины антропогенного эвтрофирования водоемов // Итоги науки и техники.
Общая Экология. Биоценология. Гидробиология. Т. 2 «Антропогенное эвтрофирование водоемов». М.: ВИНИТИ, 1975. С. 61-96.

11. Суппес Н.Е. Фауна и экологические особенности ресничных инфузорий водоемов юга Тюменской области: дис. ... канд. биол. наук. Ишим, 2010. C. $108-149$.

12. Горюнова С.И. Влияние антропогенного воздействия на экологическое состояния малой городской реки // Вестн. Моск. ун-та. Сер. 3 «Естественные науки». 2010. № 2. С. 57-64.

13. Трусилова Т.М., Севидова Л.П. Трансформация режима стока реки Ишим под влиянием каскада водохранилищ // Вестн. Тюмен. ун-та. 2003. № 2. C. $163-171$.

14. Щеглов А.Ф. Комплексный анализ территориальной социально-экономической системы Тюменского Приишимья: монография. Ишим: Изд-во ИГПИ им. П.П. Ершова, 2006. 140 с.

15. Кощеева Г.С. Особенности геохимического режима и качества вод ландшафтов Ишимской равнины: монография. Ишим: Изд-во ИГПИ им. П.П. Ершова, 2014. $172 \mathrm{c}$.

16. Кондратьев Н.Е., Попов И.В., Снищенко Б.Ф. Основы гидроморфологической теории руслового процесса. Л.: Гидрометеоиздат, 2001. 272 с.

17. Чалов Р.С., Рулева С.Н. Изменения русел рек и опасные проявления русловых процессов на урбанизированных территориях // География и природные ресурсы. Вып. 4. Новосибирск: Изд-во СО РАН филиал «Гео», 2001. С. 17-25.

18. Чертопруд М.В. Модификация метода Пантле-Букка для оценки загрязнения водотоков по качественным показателям макробионтов // Водные ресурсы. 2002. № 3. С. 337-342.

19. Жадин В.И. Методы гидробиологических исследования: учеб. пособие. М.: Изд-во «Высшая школа», 1960. С. 27-65.

20. Определитель пресноводных беспозвоночных Европейской части СССР / под ред. Л.А. Кутиковой, Я.И. Старобогатова. Л., 1997. 512 с.

\section{THE IMPACT OF ECONOMIC ACTIVITY ON THE ECOLOGICAL STATE OF THE WATER RESERVOIRS OF ISHIM}

(C) 2018

Suppes Natalia Evgenievna, candidate of biological sciences, associate professor of Biology, Geography and Teaching Methods Department P.P. Ershov Ishim Pedagogical Institute (branch) of Tyumen State University (Ishim, Tyumen Region, Russian Federation)

\footnotetext{
Abstract. This article analyzes the problem of the state of the water bodies in Ishim by anthropogenic pressures. The study shows that the water reservoirs are negatively influenced by the economic activities of the population. The author defines their main directions: industrial wastewater discharge to the city water bodies, construction and operation of engineering constructions, activity in the private sector. To assess the state of the water bodies the author uses the results of the visual assessment of the state of the riverbeds and their coastal zone, the organoleptic water indicators (turbidity, color and smell), the analysis of the hydrobiological studies (determination of the degree of saprobity of the water bodies as indicators ciliated infusoria). The study showed the satisfactory condition of all the water reservoirs and the non-critical impact. As the enterprises for light manufacturing and food industries in Ishim are not sources of chemical, organic and other pollution the visual assessment didn't reveal significant deformations of the riverbeds and any changes in the coastal zone. The impact of the private sector is local and not the significant cause of organic pollution.

Keywords: economic activity; anthropogenic impact; ecological state; ecological assessment of water bodies; eutrophication of reservoirs; Ishim; organic pollution; riverbed deformation; industrial wastewater; visual assessment; organoleptic indicators; saprobity; ciliated infusoria; Pantle and Buck's method; faunistic list.
} 